\title{
Los Testamentos de Timoteo O'Scanlan (1723-1795): Testimonio de un médico militar irlandés en la España del siglo XVIII
}

The Wills of Timoteo O'Scanlan (1723-1795): Testimony of an Irish military doctor in 18th Century Spain Michael White

Universidad Complutense de Madrid 


\section{RESUMEN}

El punto de partida del artículo actual son los testamentos, hasta ahora desconocidos, del médico militar irlandés, Timoteo O'Scanlan, afincado en España durante la segunda mitad del siglo XVIII. En primer lugar, dichos documentos, junto a otros posteriores a su muerte, nos permiten ampliar el conocimiento sobre la biografía del médico y establecer su situación económica sobre bases fehacientes. En segundo lugar, con estos hechos se analizan preguntas claves respecto a la acogida en España de la inmigración irlandesa en esa época y respecto a cómo O'Scanlan, al abrigo de su empleo militar, pudo desempeñar un papel determinante en la lucha contra la viruela tanto como teórico de la inoculación como por la práctica que ejercía de ella y, al mismo tiempo, alcanzar una estrecha integración social, profesional y económica en su país de adopción.

Palabras clave

Irlandeses en España, médicos militares, viruela, inoculación, siglo XVIII.

\section{AbSTRACT}

The starting point of the present article are the wills of the Irish military doctor, Timoteo O'Scanlan, domiciled in Spain during the second half of the 18th Century. In the first place, these documents, together with others following his death, allow us to substantially increase what has heretofore been known of his biography as well as establishing a solid basis regarding his financial circumstances. Secondly, these facts enable us to address and analyse crucial issues such as how O'Scanlan, given the historical accommodation of Irish immigration in Spain, as well as the advantages accruing from his position as military doctor, was able to carry out a key role in the struggle to curtail the disease of smallpox in the Spain of that time, promoting the technique of inoculation both in theory as in practice and, at the same time, achieve a high level of social, professional and economic integration in his host country.

Key Words

Irish-in-Spain, military doctors, smallpox, inoculation, $18^{\text {th }}$ century.

Recibido: 24 de diciembre de 2019. Aceptado: 10 de marzo de 2020. 


\section{Introducción}

A partir de la batalla de Kinsale (1601), la presencia irlandesa en los ejércitos españoles aumentó notablemente ${ }^{1}$ y duró varios siglos, abarcando tanto la Monarquía de los Austrias como la Borbónica. Las últimas décadas han conocido un gran auge tanto en la investigación como en la publicación sobre este tema ${ }^{2}$. La migración irlandesa a España no se circunscribió solamente al mundo militar, sino que también se extendió a otros muchos campos medulares, sobre todo en el siglo XVIII, como pueden ser el económico, el político y muy diversos ramos de la cultura con considerable influencia intelectual y social ${ }^{3}$. En cuanto al mundo militar, algo menos conocido es que, desde

1 Eduardo de Mesa, The Irish in the Spanish Armies in the Seventeenth Century, Woodbridge, Boydell Press, 2014; Declan M. Downey and Julio Crespo MacLellan, eds. Spanish-Irish Relations through the Ages, Dublin, Four Courts Press, 2008; Hiram Morgan (ed.), The Battle of Kinsale, Dublin, Wordwell, 2004.

2 Una vision global, abarcando desde el siglo 17 al 20, se halla en Hugo O'Donnelt, (coord.), Presencia irlandesa en la Milicia Española/The Irish Presence in the Spanish Military - 16th to 20th Centuries, Revista Internacional de Historia Militar, Madrid, 92 (2014). De las numerosas publicaciones más específicas que ponen de manifiesto la envergadura de esta presencia, véase, entre otras, Enrique García Hernán y Óscar Recio Morales, (coords.), Extranjeros en el Ejército. Militares irlandeses en la sociedad española, 1580-1818, Madrid, Ministerio de Defensa, 2007; Thomas O'Connor, The Irish in Europe, 1580-1815, Four Courts Press, Dublin, 2001; Declan M. DownEY, «Whether Habsburgs or Bourbons: Some reflections on the alignments of nobles of Irish origin in the war of the Spanish Succession, 1713-1723», en Igor Pérez Tostado y Enrique García Hernán (eds.), Irlanda y el Atlántico Ibérico. Movilidad, participación e intercambio cultural, Valencia, Albatros Ediciones, 2010, págs. 243-252; Declan M. DownEY, «Beneath the Harp and the Burgundian Cross: Irish Regiments in the Spanish Bourbon Army, 1700-1818», en O’Donnell (coord.), Presencia Irlandesa, págs. 83-105.

3 En cuanto a lo económico, destacaban muy en especial los comerciantes, particularmente los asentados en Cadiz (véase M. Carmen LaRio DE OÑate, «Casas de comercio irlandesas en el Cádiz dieciochesco», en Enrique García Hernán y Ryszard Skowron (eds.), From Ireland to Poland. Northern Europe, Spain and the Early Modern World, Valencia, Albatros, 2015, pags.195-208) y Las Islas Canarias (véase Agustín GuIMERÁ RaVINA, Burguesía extranjera y comercio atlántico: la empresa comercial irlandesa en Canarias (17031771), Santa Cruz de Tenerife, Consejería de Cultura y Deportes, Gobierno de Canarias, 1977), pero también en otros muchos lugares. En política, Ricardo Wall (1694-1777) sobresale de manera notable, en primer lugar, por su cargo en la cúspide del Gobierno del Reino, pero no menos importante por el nutrido grupo de personas de origen irlandés que obtuvieron altos cargos durante su ministerio (1754-1763). En cuanto a la cultura, inmigrantes de origen irlandés, entre otras cosas, tuvieron un importante papel en diseminar saberes adquiridos en países de otras lenguas, así como por ser pioneros en la enseñanza de la lengua inglesa y en publicaciones sobre el tema. También tuvieron un papel importante en la traducción, especialmente Pedro Sinnot (m. 1791): respecto a todos estos temas, véase Óscar Recio Morales, Ireland and the Spanish Empire 
el inicio de dicha presencia, servía en los tercios y regimientos españoles un nutrido grupo de médicos irlandeses ${ }^{4}$, algunos de los cuales desempeñaron un papel muy significativo ${ }^{5}$. Entre estos últimos, Timoteo O'Scanlan (1723-1795) es una figura de singular importancia ${ }^{6}$. Estudió medicina en París y, una vez titulado, consiguió el puesto de médico del Regimiento de Hibernia en 1754. El Regimiento participaba en las defensas de Ferrol, pero estaba sujeto a largos desplazamientos a destinos diversos. En 1766, O'Scanlan es nombrado Primer Médico de los Hospitales Reales de Ferrol, que dependían de la Marina, plaza que mantuvo hasta su jubilación en 1783. Es bien conocida la gran tradición histórica en España de la asistencia médica en las campañas del Ejército y la Armada, hasta tal punto que, como afirma Manuel García Rivas: «Nuestros historiadores militares han considerado, tradicionalmente, que el ‘hospital de campaña' fue una creación española» ${ }^{7}$. O'Scanlan participa de

1600-1825, Dublin, Four Courts Press, 2010, págs. 235-295. Véase, más adelante, la nota 37, para más información sobre estas cuestiones.

4 Véase Benjamin HazARD, “Very necessarie instrumente in a compani’: Irish medical personnel and Spanish military medicine, (1586-1685)», Ossory, Leinster, Laois, Archivium Ossoriense, 5 (2013), págs. 115145; Benjamin HazArD, «Medical services for Spanish Armed Forces in The Low Countries and Ireland, 1586-1685)», en García Hernán y Skowron (eds.), From Ireland to Poland, págs. 235-250.

5 Michael White, «The role of Irish Doctors in Eighteenth-Century Spanish Medicine», en DownEY and Crespo MacLellan, Spanish-Irish Relations, Dublin, Four Courts Press, 2008, págs. 149-174. Incluso, también hubo médicos de origen irlandés que destacaron en la medicina civil. Por ejemplo, los médicos Felix y Alexander Maguire se establecieron con éxito en Cadiz, véase Micheline Kerney WALSH, «Two 18th Century Medical Doctors in Spain, Felix and Alexander Maguire», Clogher Record, Vol. 13, No. 2, (1989), pags. 70-83; el médico Raymond Everard (1675-1760) ejerció como médico municipal en Bilbao durante casi 40 años, véase Ekain Cagigal, Raymond Everard. Un médico irlandés en el Bilbao pre-ilustrado, s. e., Bilbao, 2014.

6 El único documento con que contamos actualmente sobre la vida de O'Scanlan con anterioridad a su llegada a España en 1754 es la de la obtención de su título en Medicina en la Universidad de Reims, Francia, el 3 de julio 1754. Cotejando la información respecto a aquella etapa de su vida que aparece en la relación de sus méritos y servicios, certificada por el Comisario de Guerra de los Reales Ejércitos, Francisco Xavier Larúmbez, el 14 de febrero 1784 (AGS, GM, 6549), con más documentación española sobre él, se puede afirmar que nació en Newcastle West (condado de Limerick), con 1723 como la fecha más probable (Véase Michael Whiте, «La figura de Timoteo O'Scanlan: una revisión», Cuadernos Dieciochistas, 17 (2016), págs. 277-281). Por regla general, la inmigración irlandesa católica adolecía de falta de documentos de Irlanda porque simplemente éstos no existían. Esto originaba serios problemas para los aspirantes a las órdenes militares, las cuales exigían «instrumentos» probatorios. Los aspirantes recurrían a un historial familiar redactado ad hoc, constatando su bautizo católico en sus propios domicilios y firmado por uno o varios sacerdotes e incluso a veces, para dar más empaque, por obispos. Por ejemplo, el historial de David Lacy, tío de la mujer de O'Scanlan, para La Órden de Santiago venía firmado por cuatro obispos (AHN, Exp. 4255). Para una extensa documentación de los irlandeses que consiguieron entrar en las órdenes militares españolas, véase Micheline WaLSH (ed), Spanish Knights of Irish Origin, 4 volumenes, Dublin, Stationery Office, 1960-1978.

7 Manuel García Rivas, «Los Hospitales Reales del Ejército y Armada en las campañas militares del siglo Xvi», en Enrique García Hernán y Davide Maffi (eds.), Guerra y Sociedad en la Monarquía Hispánica: Política, estrategia y cultura en la Europa moderna (1500-1700), Volumen II, Madrid, Ediciones del Laberinto, 2006, págs. 765-784; pág. 765. 
esta tradición y resalta que, al poco tiempo de asumir el puesto en Hibernia, le tocó levantar un hospital de campaña en un desplazamiento de su regimiento ${ }^{8}$. Esto fue solo el principio, ya que posteriormente sirvió en varias campañas muy significativas, como la Guerra con Portugal (1762-3) y el Bloqueo de Gibraltar (1779-83), además de levantar un hospital provisional en la Villa de La Graña en 1770 para atender a la tropa movilizada en Ferrol por las disputas sobre las Islas Malvinas9.

El puesto de O’Scanlan en el seno del mundo militar le abría grandes posibilidades de contactos e interacción con la administración española que él supo aprovechar para desarrollar un papel más transversal en la España de la segunda mitad del siglo XVIII. Por consiguiente, además de su historial castrense, su renombre proviene del papel que desempeñó en la lucha contra la viruela — «la peste del siglo XVIII», en palabras de Domínguez Ortiz ${ }^{10}$ —. Ante la epidemia que asoló Ferrol en el año 1769-70, O’Scanlan fomentó el uso de la inoculación y, a partir de entonces, no solo la ejerció, sino que la defendió en tres libros ${ }^{11}$ y en numerosos escritos en la prensa de la época ${ }^{12}$. Esto demuestra que, aunque toda su vida laboral se desarrolló en el seno del mundo militar, el alcance de sus actividades y su obra le permitió trascender ampliamente el dominio castrense.

El punto de partida del trabajo actual es una serie de documentos archivísticos que se dan a conocer por primera vez: sus testamentos y otros documentos posteriores a su muerte, ligados a dichos testamentos. Estos documentos amplían de manera considerable aspectos hasta ahora desconocidos de su biografía. Por ejemplo, la documentación nos permite reconstruir con bastante

8 AGS, G.M, 6549, Relación de Méritos y Servicios, 14 de febrero 1784.

Claves de archivos: AHN, Archivo Histórico Nacional; AGS, Archivo General de Simancas; AGMAB, Archivo General de la Marina Álvaro de Bazán; AGMS, Archivo General Militar de Segovia; APCSFF, Archivo Parroquial Castrense de San Francisco, Ferrol; AMF, Archivo Municipal de Ferrol; AHPM, Archivo Histórico de Protocolos de Madrid.

9 AGS, G.M, 6549, Relación de Méritos y Servicios, 14 de febrero 1784.

10 Antonio Domínguez Ortiz, Carlos III y la España de la Ilustración, Madrid, Alianza Editorial, 1988, pág. 20.

11 Los títulos de los libros de Timoteo O’Scanlan son: Práctica Moderna de la Inoculación, Madrid, Hilario Santos, 1784; La Inoculación Vindicada: Carta Repulsoria de las calumnias i falsas acusaciones que contra esta práctica i sus Defensores publicó el Lic. D. Vicente Ferrer i Gorraiz, Santiago de Compostela, Ignacio Aguayo, 1786; y Ensayo Apologético de la Inoculación, Madrid, Imprenta Real, 1792. Su principal artículo en la prensa, en seis entregas, es: «Sobre la resolución del Problema de la Inoculación», Diario de Madrid, 28 de julio -2 de agosto 1790 .

12 Véase José Luis Duro Torruos, Los inicios de la lucha contra la viruela en España. Técnica e ideología durante la transición de la inoculación a la vacuna (1750-1808), Tesis Doctoral, Universidad de Alicante, 2014, especialmente págs. 100-113; Michael Whiтe, «La figura de Timoteo O’Scanlan: una revisión», Cuadernos dieciochistas, 17 (2016), págs. 275-296. 
fiabilidad su legado a su familia, el cual demuestra que su situación económica era mucho más robusta de lo que los indicios de los documentos anteriormente conocidos pudieran dar a entender. Además de proporcionar información fidedigna sobre muchos aspectos personales del médico, que por sí sola tiene importancia para ampliar el conocimiento sobre su biografía, dicha información nos facilita indagar en cuestiones más amplias como son, entre otras, el papel de la inmigración irlandesa tanto dentro como fuera de los confines del mundo militar español en la segunda mitad del siglo XVIII. El hecho de que la inmigración irlandesa tuvo su nicho de actividad, e incluso afianzamiento, en campos como la política, el comercio, la cultura y la religión, facilitaba sus interrelaciones trasversales desde unas áreas a otras y les brindaba oportunidades para contribuir a ellas y, a la vez, beneficiarse en su propio progreso económico y social en su país de acogida.

En cuanto a las fuentes aquí dadas a conocer, éstas constan de cuatro documentos testamentarios y documentos posteriores a la muerte del médico que nos aclaran el reparto de su legado. La relevancia de estos documentos estriba en el hecho de que son un instrumento que nos facilita acceder a datos fehacientes sobre su vida personal, su economía y sus relaciones que no habían sido accesibles anteriormente y que nos permiten ampliar su biografía a la vez que también conducen a una mejor contextualización de su papel en España. El hecho de que los cuatro documentos testamentarios abarcan una franca temporal de veinte años es una riqueza adicional, ya que se constatan cambios coyunturales a lo largo de este período. De los cuatro, el más completo y central es el segundo y, de ahí, es el que más se acerca a la tipología característica de los documentos testamentarios. Incluye los apartados denominados por Tuells y Duro Torrijos ${ }^{13}$ «solemnidades testamentarias» (que aseguran la validez del testamento), un bloque de «disposiciones espirituales» (que trata cuestiones relacionadas con la salvación de su alma) y un bloque de «disposiciones materiales» (que se ocupa de cuestiones como las mandas, legados y, sobre todo, constatación de herederos). Pasaré ahora a analizar, en primer lugar, en orden cronológico, los cuatro documentos testamentarios que O'Scanlan otorgó.

13 José Tuells y José Luis Duro Torruos, «Los cinco testamentos de Francisco Xavier Balmis», $G a$ ceta Médica de México, 148 (2012), pág. 413. 


\section{Documento 1}

Al suscribir este primer documento notarial ${ }^{14}$, O'Scanlan llevaba ya diecinueve años residiendo y trabajando en España. El documento no es un testamento propiamente dicho, pero tiene ciertas similitudes con uno, ya que estipula condiciones en caso de su óbito. En él, concede a su esposa, María Lacy, además de lo que le correspondería en concepto de gananciales, una suma de nueve mil reales de vellón, en el caso de que ella enviudara. Para que su esposa recibiese la dotación con prontitud, asegura la cantidad con una casa de su propiedad situada en la Plaza Nueva de Ferrol «donde actualmente vive el relojero Don Pedro Valieres» ${ }^{15}$, con lo cual, es probable que perciba ingresos adicionales como renta por dicha casa. Por otro lado, la constatación de dicha propiedad es un primer indicio de que O’Scanlan goza de una situación económica de cierta fortaleza.

\section{Documento 2}

Diez años más tarde, dicta lo que es propiamente su testamento ${ }^{16}$, el cual recoge todas las disposiciones especificadas arriba como estándar por Tuells y Duro Torrijos. En cuanto a las «disposiciones espirituales», hace una detallada profesión de fe, suplicando clemencia, con absoluta humildad, a su Creador. Es significativo que también esa humildad se aflora con respecto a su entierro, insistiendo que sea «sin pompa ni fausto» y que las misas por su alma sean simplemente «misas rezadas» (es decir no cantadas). En cuanto a las «disposiciones materiales», ratifica la dotación de 9,000 reales ya asignada a su esposa en el primer documento.

A continuación, el testamento pone de manifiesto dos situaciones familiares que condicionan y condicionarán las actuaciones futuras de O’Scanlan: la salud mental de su esposa y la corta edad de sus hijos, ocho y seis años respectivamente. Ya en los primeros años del matrimonio habían surgido problemas de convivencia. Amenedo Costa descubrió una documentación interesante ${ }^{17}$ en la

14 AHPM 19.250, f. 577- 8, otorgado ante Don Manuel Llorente y Acero, 6 de septiembre 1773. O'Scanlan firma esta escritura el mismo día en que se casa con María Lacy.

15 AHPM 19.250, f. 578.

16 AHPM 20.588, ff. 199-202, 26 octubre 1783. Notario: Don Francisco Xavier Ramiro.

17 Mónica Amenedo Costa, «Timoteo O’Scanlan: Vida pública y privada en El Ferrol Ilustrado», Revista Garoza, 10, (septiembre 2010), págs. 9-22. Esta documentación es la única conocida hasta la fecha que recoge una perspectiva propia de María Lacy. En ella se vislumbra una mujer de fuerte carácter y con confianza en el estamento militar, donde cuenta con tres tíos carnales como altos oficiales. 
cual se constata que, poco después del nacimiento de su hijo, O'Scanlan había acudido a las autoridades eclesiásticas denunciando un comportamiento de su esposa que, sostenía, le legitimaba, según el Derecho Canónico, para solicitar una separación Quoad Toram ${ }^{18}$. Aquel documento no mencionaba la salud mental de su esposa, pero los testamentos y varios documentos posteriores sí constatan su desequilibrio mental ${ }^{19}$.

Ante la incapacidad de su esposa se ve en la necesidad de nombrar un tutor para sus hijos. Escoge para el cargo al Conde de Lacy (1731-1792), pariente de María, y manifiesta respecto a él: «de quien espero como así lo ha prometido por el mucho amor y cariño que S. E. me tiene cuidara de los citados mis hijos en sus adelantamientos y bien estar» ${ }^{20}$.

Dado el alto perfil militar del Conde, no es arriesgado pensar que O'Scanlan tiene ya en mente un futuro castrense para su hijo, y un tutor de alto rango en la profesión podría facilitar su 'adelantamiento'.

La cuestión de su legado y la preocupación para salvaguardarlo van a ser una constante en éste y, especialmente, en los documentos testamentarios posteriores. Aunque nombra como sus herederos por partes iguales a sus hijos y a su esposa, puntualiza que los herederos del patrimonio acumulado con anterioridad al matrimonio son únicamente sus hijos, constatando que ese patrimonio incluía no solo uno sino dos inmuebles, un indicio más de la solidez de su economía ya en la época en que suscribió el primer documento.

Es interesante señalar que O'Scanlan era reacio a dejar su testamento cerrado, ya que añadió una cláusula para que pudiera quedar abierto a modificaciones posteriores, simplemente dejándolas escritas por su mano. Dada la preocupación que le generaba el doble condicionante de la incapacidad mental de su esposa y la corta edad de los hijos, está testando algo temprano, pero estableciendo una vía flexible respecto a introducir modificaciones que los acontecimientos futuros pudieran necesitar o aconsejar.

\section{Documento 3}

Cinco años más tarde, O'Scanlan añade un codicilo ${ }^{21}$, ratificando al Conde como tutor para sus hijos, eximiéndole de toda reclamación posible por respon-

18 APCSFF, Caja Núm. 426.

19 AGMAB 620/865, Solicitud de 4 meses de licencia para T. O’Scanlan y Lacy de Juan M. de Cárdenas y Edmundo O'Ryan a Don Pedro Barela y Ulloa, 13 noviembre 1795; AHPM 21,378, 4 julio 1796.

20 AHPM 20.588, f. 201r.

21 AHPM 20.972, ff. 264-265. 
sabilidades y concediéndole facultades para nombrar y sustituirse con suplentes para desempeñar el encargo. Vuelve a constatar que su mujer «se halla demente» y añade que, al estar él incorporado al Monte Pío de Madrid, ella «debe gozar diez reales Vn diarios de viudedad». Faculta al Conde para que pueda aumentar dicha cantidad, pero «con consideración a mis cortos haberes» ${ }^{22}$.

\section{Documento 4}

El quince de agosto de 1795, una semana antes de su fallecimiento, O'Scanlan hizo un segundo codicilo, ante el notario Don Casimiro Antonio Gó$\mathrm{mez}^{23}$. En esta ocasión, se percibe un cambio en sus prioridades. Su preocupación por el «adelantamiento» de sus hijos en posicionarse bien en el mundo, tan destacada en los documentos 2 y 3 , no aparece en el $4^{\circ}$ documento, donde la prioridad es que su legado pase intacto a sus herederos y que se eviten procedimientos que pudieran mermar el caudal o alargar el proceso. Sus hijos, de 20 y 18 años, siguen en minoría legal de edad.

Como el Conde de Lacy ya había fallecido, nombra como tutores, albaceas y supervisores de su legado, a Edmundo O'Rian, presbítero y Administrador del Real Hospital de San Andrés de los Flamencos, a Diego O'Connor, cambista, y a Manuel de Cárdenas, médico castrense y protomédico de La Coruña. Dos son de origen irlandés y el tercero, al igual que O’Scanlan, médico militar. Se observa el patrón por el cual, para asuntos importantes y vitales, se recurre a otros inmigrantes irlandeses e igualmente a personas de la misma profesión. (La tabla 1 sintetiza lo más destacado de los cuatro documentos).

\section{La situación económica de O'Scanlan a la luz de sus testamentos y otros documentos}

Las constataciones respecto a la economía del médico son algo contradictorias. Por un lado, el hecho de que era dueño de dos inmuebles y de que pudo hacer una provisión de una dotación de 9.000 reales a favor de su esposa el día de su boda implica una economía sólida. No obstante, cuando plantea fondos adicionales para el cuidado de su esposa enferma, especifica que éstos

${ }^{22}$ AHPM 20.972, f. 264v. También en sus peticiones para mercedes, O’Scanlan solía subrayar que sus recursos económicos eran escasos. Véase AGS, Sec Guerra, leg. 6549, solicitud de una asignación para su hija, 8 abril 1791.

23 AHPM 21.736, ff. 547-550. 


\section{Tabla 1. Puntos más destacados de cada testamento}

Documento 1

6 septiembre 1773

Notario:

Manuel Llorente y Acero

\section{Documento 2}

26 octubre 1783

Notario:

Francisco Xavier Ramiro

\section{Documento 3}

15 octubre 1788

Notario:

Ignacio de Salaya

\section{Documento 4}

15 agostol795

Notario:

Casimiro Antonio Gómez
Dotación de 9.000 reales para María Lacy en el caso de que enviudara

Los futuros hijos serán herederos únicos del patrimonio que O'Scanlan tenía previo a su matrimonio

Testigos: Franco García Calderón, Martín Malsay, Gregorio Rodriguez.

Profesión de fe y detalles de entierro, evitando pompa y gastos excesivos

Constatación de la incapacidad de María Lacy por enfermedad mental

Ratificación de la dotación del documento 1

Nombramiento como tutor de sus hijos (8 y 6 años) al Conde de Lacy, expresando confianza en que les ayude en sus «adelantamientos»

Nombramiento como herederos a su mujer e hijos

Constatación que posee 2 casas en Ferrol, que son herencia exclusiva de sus hijos ya que eran de su propiedad previamente a su matrimonio

Petición de que se incorporen al testamento las disposiciones que pudiera dejar por escrito con el trascurso del tiempo

Albaceas: J ${ }^{\text {ph }}$ Mateo Moreno, Luis Meagher y O'Brien y Mauricio Echandi

Reiteración de la incapacidad de María Lacy

Ratificación como tutor al Conde de Lacy, eximiéndole de responsabilidades, concediéndole amplios poderes y pidiendo nuevamente su ayuda para el «adelantamiento» de sus hijos

Constatación de que, al estar él dado de alta en el Monte Pío, María Lacy tendrá derecho a 12 reales diarios por viudedad y faculta al Conde de Lacy a añadir a esta cantidad lo que estime oportuno

Nombra albaceas a Diego O'Connor y Juan Antonio Andacobeitia

Ratificación de los documentos anteriores

Insistencia en que, para ahorrar gastos, su herencia se reparta de manera amigable y extra-judicial

Nombramiento como tutores, albaceas y contadores a Edmundo O'Rian, Diego O’Connor, y Manuel de Cárdenas 
tienen que ser acordes con sus «cortos haberes», algo que denotaría una economía débil. Salvando estas referencias, los testamentos no ofrecen más datos concretos de su economía. Frecuentemente, detalles de esa naturaleza no aparecían en los testamentos sino en los inventarios posteriores al fallecimiento ${ }^{24}$. Dada la insistencia de O'Scanlan a sus contadores y albaceas para que se hiciera un reparto no judicial, no parece que se diera este paso en su caso. No obstante, aunque no haya inventario, sí que existen documentos posteriores a su muerte que nos aproximan a su legado real. De todos estos documentos, el más importante es el inventario de los bienes de Timoteo O'Scanlan de Lacy ${ }^{25}$, elaborado en preparación para su futuro matrimonio con Margarita Shelly ${ }^{26}$. Al corresponder los activos de Timoteo hijo casi exclusivamente a la herencia de su padre, proporcionan datos fehacientes de su legado. También, el documento constata que la hija del médico, María O'Scanlan de Lacy, había fallecido repentinamente unos meses posteriores a la muerte de su padre, dejando a Timoteo hijo como descendiente único. Igualmente, el documento revela que Margarita Shelly es sobrina de Edmundo O'Rian y Shelly, el primer nombre de las listas de albaceas y tutores del último testamento. Esta situación de futuro enlace matrimonial de Timoteo hijo con esta familia de considerables medios económicos $^{27}$ y el afianzamiento en su carrera en la Marina explican el cambio de énfasis en el último codicilo. Además, todas estas circunstancias que contribuyeron a este enlace nos demuestran cómo los inmigrantes irlandeses aprovechaban su entorno de sociabilidad para concertar matrimonios económicamente beneficiosos y de esa manera consolidar el ascenso de sus herederos en su país de acogida.

Salvando el apunte de los 9.000 rs (sueldo que la Marina le debe a Timoteo hijo), todo lo demás, en buena lógica, procedería de la herencia de su padre. La carencia de referencia a provisiones para María Lacy deja la incógnita de si la suma final es solo la parte del legado que ha correspondido al hijo o si, dada la incapacidad mental de María Lacy, su parte también ha pasado a la administración de su hijo, en cuyo caso el inventariado correspondería a la totalidad de la herencia. Por el contrario, si la parte de la herencia que correspondiera a María

${ }_{24}$ Un buen ejemplo son los testamentos y el posterior inventario del médico Balmis, documentados en Tuells y Duro Torrijos, «Los cinco testamentos», pág. 154.

25 Timoteo O'Scanlan de Lacy (1774-1831) fue Capitán de Fragata y autor del primer diccionario de términos de construcción naval.

26 AHPM 21.738, 4 julio 1796, ff. 119-132.

27 Margarita Shelly era hija de comerciantes que ya habían fallecidos, de manera que, en el momento de la elaboración del documento notarial del inventario de los bienes de Timoteo hijo, ella ya había heredado y, en la misma acta notarial, hace un inventario aparte de sus propios bienes, que aportará como dote al futuro matrimonio y que suman un valor considerable: 1.170 .973 reales. AHPM 21.738, 4 julio 1796, ff. 138-147. 
Lacy ya estuviera desgajada y asignada a ella, el valor total de su legado sería aun considerablemente mayor.

Desglosando los bienes de Timoteo hijo según apartados, se podría establecer un primer bloque que comprende inmobiliario, dinero en efectivo e inversiones. Consta de cinco entradas que suman un total de $245.519 \mathrm{rs}$, sin duda una cifra considerable. Las dos casas en Ferrol, por ejemplo, se valoran en 89.519 rs. Un segundo bloque comprende vestuario y productos textiles de distintos materiales y orígenes. Consta de 33 objetos de ropa blanca y 8 objetos de ropa de color que suman en conjunto un valor de $7.262 \mathrm{rs.} \mathrm{El} \mathrm{tercer} \mathrm{bloque}$ comprende oro, plata (valorada en función de su peso, a razón de 20 rs la onza) y otros objetos de valor y consta de quince entradas que suman un total de 8.828 reales. Finalmente, se incluye un crédito debido al médico por un pago que se vio obligado a saldar en calidad de fiador en un fallido negocio de importación de productos cubanos, dirigido por Diego Goold. El importe es verdaderamente significativo - $157.940 \mathrm{rs} \mathrm{V}$ - y se especifica que sería difícilmente recuperable por falta de bienes de los deudores y el paso del tiempo. Que el médico se hubiera implicado hasta tal extremo en un asunto comercial de esta envergadura abre interrogantes. La incógnita principal (que abordaré más adelante) es si su participación en estas actividades haya sido meramente coyuntural o más habitual. (Véase los detalles del inventariado en la tabla 2).

O'Scanlan como ejemplo de la integración de los emigrantes irlandeses en la España del Siglo XVIII

Contrariamente a otros irlandeses de distinguidas carreras en España que llegaron al país a muy cortas edades ${ }^{28}$, O'Scanlan llegó teniendo 30 años, una edad que hubiera podido dificultar su integración y sus posibilidades de labrarse un futuro prometedor. Sin embargo, la documentación anterior demuestra un éxito económico ${ }^{29}$ que, como veremos, se extiende a otros campos, como la

${ }_{28}$ Por ejemplo, Ricardo Wall, Alejandro O'Reilly y Felix O'Neill llegarían a España con edades en torno a los diez o quince años. Véase Diego Téllez Alárcia, D. Ricardo Wall. Aut Caesar aut nullus, Madrid, Ministerio de Defensa, 2008, págs. 57- 8; Óscar Recio Morales, «Una aproximación al modelo del oficial extranjero en el ejército borbónico: la etapa de formación del teniente general Alejandro O'Reilly (1723-1794)», Cuadernos Dieciochistas, 12 (2011), págs. 171-195.

29 Incluso, comparativamente, su legado es mayor que el de otras figuras contemporáneas importantes. Por ejemplo, vemos que «un total de 261.000 reales representa el grueso» del legado de Ricardo Wall (16941777), TÉllez Alárcia, D. Ricardo Wall, pág. 320; y Francisco Xavier Balmis (1753-1819) dejó en efectivo, inversiones y créditos, un total de 210.938 reales, véase Tuells y Duro Torrios, «Los cinco testamentos», pág. 417. 
Inmobiliario, dinero en efectivo e inversiones Reales de Vellón

2 casas en Ferrol. . . . . . . . . . . . . . . . . . . . . . . .

10 acciones del Banco San Carlos. . . . . . . . . . . . . . . . . .

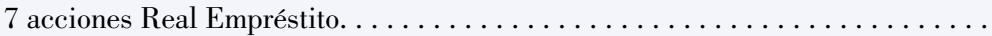

Dinero en efectivo (a invertir también en Real Empréstito)

Invertido en Renta de Tabaco . . . . . . . . . . . . . . . . . . .

(Sueldo pendiente de Timoteo hijo: 9.000rs que no contabilizo)

Vestuario, telas, etc.

Ropa blanca: 33 artículos descritos - Muestra de los más destacados:

Pieza de Lienzo de Flandes para camisas de 26 varas a 19 1/2 rs la vara . . . . . .

Seis camisas finas de lienzo de Flandes a 68 rs cada una . . . . . . . . . . . .

Doce pañuelos de muselina para el cuello a 20 rs cada una . . . . . . . . . . .

Doce pañuelos de colores para faltriquera a $16 \mathrm{rs} \ldots \ldots \ldots \ldots \ldots \ldots \ldots$

Tres chalecos de cotonia inglesa a 50 rs

Ropa de color: 8 artículos descritos — muestra de los más destacados:

Una casaca y chupa de uniforme de Marina con sus galones de oro . . . . . . . .

Uniforme completo con dos pares de calzones . . . . . . . . . . . . .

Uniforme nuevo con calzones de Ingeniero Extraordinario de Marina . . . . . . . .

Una capa de paño muy fino, poco usada, color de verde botella

Plata, oro y otros objetos de valor

Juego de 4 hebillas de oro para zapatos . . . . . . . . . . . . .

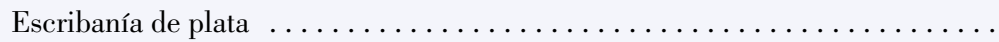

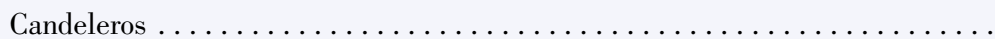

Salvilla . . . . . . . . . . . . . . . . . . . . . . . . . . . . . 1.150

Reloj de cilindro, Hermanos Charvert. . . . . . . . . . . . . . . . . . . . . 2.040

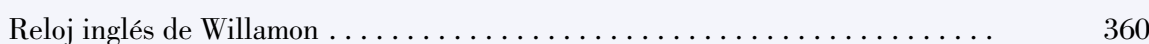

Otros 9 objetos diversos

Crédito que pagó O’Scanlan como fiador. 
vida en el entorno militar, la profesión médica, el mundo de las letras y la vida social española en general.

O'Scanlan llegó a Ferrol en 1754, justo en pleno despegue de las impresionantes obras militares del gran arsenal, que ya empleaba quince mil personas como mano de $\mathrm{obra}^{30}$. Posteriormente, ya en la década de los 60, dicho despegue condujo a un gran impulso de desarrollo urbano, autorizado por Carlos III, para acomodar el enorme incremento de su población atraída por la actividad del arsenal. Esta afluencia de personal contaba también con gran número de técnicos, ingenieros, altos cargos civiles y militares, incluyendo Jorge Juan, que creaba un núcleo cultural elevado en Ferrol. El hecho de que O'Scanlan había adquirido dos casas en Ferrol con anterioridad a su matrimonio en 1773, como consta en los testamentos, demuestra que había sabido aprovechar la ocasión que brindaba este gran desarrollo para hacerse con esas propiedades ${ }^{31}$. No obstante, si uno se atiene a los ingresos del médico provenientes de su empleo oficial en ese momento, una inversión de tal calibre podría parecer más allá de sus posibilidades. Por lo tanto, debería tener ingresos provenientes de otras fuentes ${ }^{32}$. Veremos más adelante que tenía remuneraciones adicionales por sus actividades como inoculador, pero dichas actividades en su mayoría serían posteriores a la adquisición de las casas.

Su implicación en una operación comercial con una suma muy considerable deja incógnito si ésta fuera solamente una operación puntual o si participara en dichas actividades más habitualmente. No hay constatación de que O'Scanlan se involucrara en más operaciones comerciales, pero ciertas circunstancias coyunturales sugieren que esta última podría ser una posibilidad. Primero, al abrigo del desarrollo exponencial de Ferrol en el siglo XVIII ${ }^{33}$, figuran distintos

30 Alfredo Vigo Trasancos, «ESTA OBRA SUBLIME ES LA SEÑAL DE UN GRAN REY»: LA CIUDAD-ARSENAL DE FERROL O EL SUEÑO PORTUARIO DEL MARQUÉS DE LA ENSENADA (17471754), Cuadernos dieciochistas, 17, (2016), pags. 47-71.

31 Este desarrollo urbano está documentado en Alfredo Vigo Trasancos, «El Conde de Vega Florida y el inicio de la Nueva Población de Ferrol (1761-1771)», Ferrol Análisis: revista de pensamiento y cultura, 31 (2018), págs. 9-21.

32 Los 100 escudos mensuales de sueldo como médico de Hibernia se redujeron a 60 al pasar a Primer Médico de los Hospitales, AGS, Marina, Leg. 221, f. 434, Confirmación de salario, 26 de septiembre 1766. Una vez nombrado, solicita aumentos y su sueldo para el año 1771 ya alcanzaba 7.030 reales: AMF, C-877, exp.1, f. 64. Véase también, Mónica Amenedo CostA, «Foreign Immigration: The economic situation of some British workers in Ferrol in the eighteenth century», en Elizabeth Vigo Woodward Smith (ed.), Approaching cultures through English, A Coruña, 2007, págs. 25-30.

33 Llegó a tal pujanza que su crecimiento demográfico en la segunda mitad del siglo XviII rebasó el mil por ciento, convirtiendo a Ferrol en la ciudad más poblada de Galicia: «a finales de siglo, la real villa era un centro urbano de cierta entidad en el contexto general español y la primera ciudad del reino de Galicia en cuanto a número de habitantes», Alfredo MarTín García, Población y Sociedad del Ferrol y Su Tierra en el Antiguo Régimen, Tesis doctoral inédita, Universidad de A Coruña, Vol I, 2001, pág. 49. 
residentes de origen irlandés que se dedicaban al comercio, y existe una estrecha relación entre O'Scanlan y varios de ellos ${ }^{34}$. Al haber quedado constatación de la participación de O'Scanlan en una operación comercial con Diego Goold ${ }^{35}$ con una suma fuerte y que se relacionaba estrechamente con otros comerciantes de origen irlandés, es hipótesis plausible que pudiera haber participado en más operaciones con estas personas.

¿Qué factores podrían explicar la integración de O’Scanlan en la España del xviII? En primer lugar, el hecho de que un médico irlandés recién titulado en Francia, sin experiencia previa alguna en el oficio, tome posesión como médico del Regimiento Hibernia (situado en Ferrol, pero con frecuentes y prolongados desplazamientos) escasos meses después, demuestra la integración ya y la capacidad de las redes de contacto, solidaridad y poder de los irlandeses ya establecidos en el país. Pudieron facilitar la contratación de un aspirante a establecerse, novato en el oficio, en un puesto relevante en un tiempo muy breve. Además, la llegada de O'Scanlan en 1754 coincide con el inicio del ministerio de Ricardo Wall, período de gran protagonismo de la inmigración irlandesa en diversos campos y puestos de la vida y la administración españolas, hasta tal punto que se habla de esta colectividad como Irish Party ${ }^{36}$. Aunque no existía tal partido, sí que hubo, en las primeras décadas de la segunda mitad del siglo XVIII, una presencia irlandesa muy considerable en campos muy diversos, donde algunos desempeñaron papeles muy singulares, aportando conocimiento del exterior en beneficio de la marcha del país y, por otro lado, muchos se beneficiaron social y económicamente de las oportunidades que España les brindaba. Respecto a esto, O’Scanlan es uno más en ambos sentidos y la labor de estos destacados personajes de la inmigración irlandesa muestra la pauta de sus interrelaciones entre sí, por un lado, y, por otro, su conexión y colaboración con personas y figuras relevantes de su país de adopción ${ }^{37}$.

34 Por ejemplo, como documenta Amenedo Costa, La población británica, págs. 76, 92 y 104 , O'Scanlan figura como testigo o padrino en los matrimonios o bautismos de los hijos de comerciantes como Luis Meagher, Luis O'Brien y Diego Goold. O'Brien y Meagher tenían además relaciones fluidas con la administración al desempeñar servicios consulares para la población irlandesa e inglesa y recopilaban sus datos para el censo.

35 El hecho de que O'Scanlan fuera testigo para el matrimonio de Goold con Úrsula Hallorán, en mayo de 1776, (Véase Amenedo Costa, La población británica, pág. 92) indicaría, en principio, que existiría una relación personal y social muy estrecha entre ambos y que esta relación pudiera haber facilitado que O'Scanlan entrara en negocios comerciales con él.

36 Véase el apartado «El Irish Party» (pags. 131-160) en Diego Téllez Alarcia, Absolutismo e Ilustración en la España del siglo XVII. El Despotismo Ilustrado de D. Ricardo Wall, Fundación Española de Historia Moderna, Madrid, 2010; véase también Recio Morales, Ireland and the Spanish Empire, págs. 254-269.

37 Además de figuras muy distinguidas en lo militar y político, como eran Ricardo Wall (1694-1777) y Alejandro O'Reilly (1723-1794), los irlandeses tuvieron gran protagonismo en el comercio, especialmente 
Por otro lado, el puesto le coloca en un entorno repleto de oportunidades de contactos profesionales y sociales dentro y fuera de la inmigración irlandesa: estos dos factores contribuirán de manera clave a su éxito en España. Aunque en aquella época, en España, el médico castrense no es todavía un militar de carrera con sus correspondientes vías de ascenso jerárquico — ese paso no se da hasta bien entrado el siglo XIX - goza de seguridad en el puesto, un estatus reconocido y un prestigio que le confiere una estrecha integración en asuntos del mundo militar, relacionándose con todos los rangos de su regimiento y con vías de acceso a distintas esferas de la administración española ${ }^{38}$.

Su paso a Primer Médico de los Hospitales Reales de Ferrol le abre un abanico de relaciones todavía más transversales con la administración española. Al depender de la marina, este puesto supone un salto cualitativo en cuanto que transciende la órbita de la influencia irlandesa. Al solicitar el puesto, O'Scanlan

en Las Islas Canarias y en Cadiz (Véase, la nota 3 arriba). También, han destacado en diversos campos de la cultura, siendo significativa su contribución en publicaciones: por ejemplo, el pensamiento y las obras de Bernardo Ward (muerto en 1776) han servido como fuentes para el Conde de Campomanes; en cuanto al área de la lingüística, la labor de irlandeses en la traducción, la publicación de gramáticas, diccionarios y la enseñanza de lenguas ha sido muy significativa. Como botón de muestra, se podría mencionar a personajes como el clérigo Pedro Sinnot (muerto en 1791, véase Eva Velasco Moreno, «Pedro Sinnot, la obra intelectual de un clérigo irlandés en España», en María Begoña ViLLAR GaRcía (coord.), La emigración irlandesa en el siglo XVIII, Universidad de Málaga, 2000, pags. 229-243). Sinnot era traductor del Rey y tradujo, entre otras muchas cosas, el libro de divulgación médica del galeno escocés, William Buchan (1729-1805), Domestic Medicine, libro muy innovador y popular en la Gran Bretaña del XVIII (véase James KelLY «Domestic medication and medical care in late early modern Ireland», en James Kelly and Fiona Clark (eds.), Ireland and Medicine in the Seventeenth and Eighteenth Centuries, Farnham, Ashgate, 2010, págs. 109-135), siendo innovador también en la España del xVIII por su manera de abordar los temas médicos con un lenguaje llano, tratando cuestiones de salud y enfermedades muy cotidianas, tanto leves como graves. O'Scanlan reprodujo en su Ensayo Apologético (pags. 270-297) el capítulo dedicado a la inoculación de este libro de Buchan. Las publicaciones en España por autores de origen irlandés abarcaban campos sumamente diversos: por ejemplo, Guillermo Bowles publicó su Introducción a la Historia Natural y a la Geografía Física de España en 1755 y Enrique Doyle (1725-1799) publicó un libro muy influyente (cuatro ediciones, en 1785, 1797, 1799, 1804, edición póstuma), Tratado sobre el cultivo, uso y utilidades de las Patatas ó Papas, Madrid, Imprenta Real. A partir de la segunda edición, el libro incorporó una larga valoración muy positiva de la patata por parte de O'Scanlan, apoyando fuertemente su cultivo para consumo humano (destinando solamente lo sobrante para forraje), señalando su papel clave en la alimentación humana en Irlanda y especificando su valor dietético, diversas opciones culinarias, su potencial tanto para suplir la falta de trigo en años de escasez como para abastecer al país y aliviar costes a los más pobres. Concluye, muy acorde con el principio, tan apelado por el médico, del bien público: «se ve la suma necesidad de animar y extender este tesoro público por todo el Reyno en beneficio del Estado» (pag. 38). Véase, la tercera edición, 1799, pags. 31-38 (O'Scanlan le envió su contribución a Doyle, el 1 de octubre de 1793).

38 Durante su ausencia para servir en el Bloqueo de Gibraltar, por anomalía administrativa, se nombró otro titular para su puesto en Ferrol. El recurso de O'Scanlan (que prosperó) subraya el nexo contractual inquebrantable entre él y, en última instancia, el Rey: «Tengo el honor de exponer a V.E, para la Soberana inteligencia del Rey Nuestro Señor, que á no haver fallecido o delinquido Don Timotheo Oscanlan Médico Primario de dicho Hospital, solo equivocadamente podría haverse dado á S.M. por vacante su Plaza». AGS, Marina, Leg. 224, Exp 121, f. 569, Informe de Dn Muzio Zona al Marqs Gonzalez de Castejon, 17 febrero 1780. 
apelaba a su preparación y suficiencia para un puesto en «qualquier ospital del Rey ${ }^{39}$, pero es doblemente indicativo de dónde proceden los apoyos externos a su favor. Nuevamente, en primer lugar, recurre a la comunidad irlandesa, dando el nombre de un prestigioso y bien colocado médico irlandés, Diego Purcell ${ }^{40}$, como informante de su idoneidad. Dado el historial de Purcell y su perfil y prestigio en el mundo de la medicina, su valoración, por sí solo, debiera bastar para justificar una decisión favorable, pero es muy indicativo que además de su propio aval, Purcell agrega la percepción de los méritos de O'Scanlan que profesaban dos españoles de gran peso, Jorge Juan y el médico Andrés Piquer ${ }^{41}$. Que dos destacadas figuras españolas tengan en tal alta estima a O'Scanlan demuestra la valía de éste, a la vez que da testimonio de su grado de integración ya en la sociedad española, integración que su nombramiento como Primer Médico de los Reales Hospitales no hará sino potenciar.

$\mathrm{Su}$ apuesta incondicional por la inoculación le convierte a O'Scanlan en personaje relevante en el último tercio del siglo XVIII español. Por ejemplo, $L a$ Gaceta de Madrid informa de sus inoculaciones, y su reputación respecto a la viruela le abre paso al nombramiento como miembro de la Academia de Medicina de Madrid, titulando su discurso de entrada «Sobre la utilidad, seguridad y suavidad de la inoculación ${ }^{42}$. Su economía también saldría reforzada por su actividad como inoculador. Aunque él afirmaba que nunca había cobrado nada por la cuarta parte de todas las inoculaciones que llevara a cabo ${ }^{43}$, también sus servicios como inoculador eran requeridos entre altos cargos de la administración, oficiales de los ejércitos, familias de la nobleza, del mundo financiero y comercial e, incluso, entre la profesión médica misma para inocular a sus hijos ${ }^{44}$. Estos servicios le habrían reportado, además de relaciones con estos círculos, beneficios económicos adicionales a sus ingresos oficiales ${ }^{45}$.

39 AGS, Marina, Leg 221, Exp 80, f. 436-7, 26 septiembre 1766.

40 Purcell fue médico de Hibernia, Protomédico de la Marina y finalmente Médico de Cámara de Fernando VI y Bárbara de Braganza.

41 Andrés Piquer (Fórnoles, Teruel 1711-1772), autor de numerosos libros, era profesor universitario, médico de Cámara de Fernando VI, miembro de La Real Academia de Medicina de Madrid y del Protomedicato, posición desde la cual se opuso a la inoculación.

42 Véase José TuelLs, «'Sobre la utilidad, seguridad y suavidad de la inoculación (1779)’. Discurso de Timoteo O'Scanlan (1726-1795) en la Real Academia de Medicina», Vacunas, (January-April, 2014), págs. 63-68.

43 «Declaro que de los muchos que he inoculado, la quarta parte de ellos a lo menos, no me han entregado el mas leve honorario, remitiéndolo gustoso, a unos por pobres, i a otros por amigos», O'SCANLAN, $L a$ Inoculación Vindicada, págs. 41-2.

44 Por ejemplo, entre otros, O'Scanlan inoculó a los hijos de aristócratas como la Marquesa de Aranda y los Condes de Fefiñanes, de financieros como Francisco Cabarus y Diego O'Connor e incluso de colegas médicos como Sebastián Creagh, Manuel de Cárdenas y Mauricio de Echandía.

45 O'Scanlan no pedía honorarios por estos servicios particulares, pero dichas familias le correspondían, motu proprio, con gratificaciones generosas. Por ejemplo, Don Martín Martija Herrador le gratificó 
Un ejemplo de cómo su puesto de médico militar le facilita a O'Scanlan oportunidades para sumar méritos extraordinarios y beneficiarse de ellos lo encontramos durante su servicio en el Bloqueo sobre Gibraltar (1779-83). En el transcurso de la contienda estalló una epidemia de viruela entre las fuerzas españolas y francesas. Todos los miembros del equipo médico francés enfermaron, de manera que O'Scanlan no solo se ocupó de las fuerzas españolas sino de las francesas, incluyendo los propios médicos franceses. Terminada la contienda, el Rey de Francia, Luis Xvi, mandó a través de su Embajador un caluroso agradecimiento a O'Scanlan, junto con su nombramiento como Médico Consultor de los Ejércitos de Francia y una gratificación de 50 luises de oro ${ }^{46}$. O'Scanlan rápidamente pone la distinción en conocimiento a sus superiores en la Marina ${ }^{47}$.

La obtención de la jubilación en $1783^{48}$ le permite a O’Scanlan iniciar una etapa de gran proyección pública. Reside en la corte, participa estrechamente en la Academia de Medicina de Madrid y embarca en una intensa labor literaria promocionando la inoculación: interviene frecuentemente en la prensa y publica tres libros, el último en la Imprenta Real. Todo esto le convierte en el defensor más visible y destacado de la inoculación y, también, se multiplican las referencias a inoculaciones llevadas a cabo siguiendo su método, tanto en España como en Hispanoamérica ${ }^{49}$. Además de la información teórica y práctica sobre la enfermedad en sí, estas publicaciones demuestran una gran sintonía del autor con preceptos fundamentales del siglo XVIII español, como podrían ser el papel de la ciencia, el objetivo del bien público, la salud pública como una prioridad ${ }^{50}$ y el fortalecimiento de la nación contando con mejoras económicas y aumentos de población ${ }^{51}$. Al ser estos unos objetivos muy señalados y

con «dos doblones de a ocho por sus dos chicos, me los pagó garvosamente, sin jamás pedirle yó nada». O’Scanlan, La Inoculación Vindicada, págs. 38-39, y pág. 200.

46 AGMAB, 2898/113. Informe de Ministére de la Guerre, Vicennes, notificando la distinción. julio 1784.

47 AGMAB, 2898. Carta de O’Scanlan informando sobre la condecoración: «Muy Sr Mío, Persuadido de la satisfacción que tendrá V.E. en saber que un subalterno suyo que ha servido diez y seis años en la Marina de los treinta que esta sirviendo a S.M. lograse el honor de ser atendido por otro monarca, tomo la libertad de participar a V.E. como el Rey de Francia se dignó nombrarme Médico Consultor de sus Rs Campos y Ejercitos, mandando a su embajador entregarme la Patente y una gratificación extraordinaria de 50 Luises de oro», Madrid, 1 de octubre 1784. En cuanto a la equivalencia en moneda española de la época, los 50 luises de oro valdrían aproximadamente 2.160 reales de plata, o 270 reales de a ocho, una moneda de referencia de la época. (Mis agradecimientos a Carlos Fernández-Andrade Marín por su gran ayuda con las equivalencias monetarias).

48 Finalizado el Bloqueo de Gibraltar se le concedió la jubilación, con una pensión inicial de 750 reales de vellón mensuales (9.000 rv anuales). AGS, Marina, Leg 225, Exp, 57, f. 316. Comunicación del aviso del Conde de Gausa, 26 de julio 1783.

49 Véase Paula de Demerson, "La práctica de la variolación en España", Asclepio, 45:2 (1993), págs. 3-39.

50 Cita frecuentemente el aforismo ciceroniano salus populi suprema lex esto.

51 En palabras de Domínguez OrTiz, Carlos III, pág. 115, «Todo intento de robustecer el Estado Español requería una política demográfica que atenuara la triste realidad de la población de España». 
apoyados por destacadas figuras del Gobierno de Carlos III, el alineamiento de O'Scanlan con ellos le brinda mayores oportunidades de relación e integración con círculos importantes de la administración y de la vida y cultura españolas de la época.

Con respecto a la ciencia, se decanta por su enfoque y método que, recalca, descansa sobre la observación, la experiencia y el saber contrastado ${ }^{52}$. Se esforzaba en recopilar datos constatados por escrito sobre la incidencia de la viruela, las inoculaciones que se habían llevado a cabo y sus resultados. En segundo lugar, también es innovador en España en aplicar a estos datos parámetros estadísticos, afianzando sus argumentos en números, porcentajes y proporciones ${ }^{53}$. En tercer lugar, como otras figuras de la ilustración, muestra una firme creencia en los avances contemporáneos de la ciencia, figurando entre éstos la propia inoculación ${ }^{54}$. O’Scanlan —que estaba muy al tanto de las publicaciones del momento en inglés y francés además de aquellas en español y latín ${ }^{55}$ — reivindicaba el carácter trasnacional de este desarrollo de la ciencia, pero sin menoscabo del papel español en ello: por ejemplo, coloca a Jorge Juan a la altura de Newton $^{56}$. Finalmente, en octubre de 1792, O'Scanlan tuvo el honor de presentar su recién publicado Ensayo Apologético de la Inoculación al Rey Carlos IV

${ }_{52}$ Es un tema recurrente en todas sus obras. Véase O'Scanlan, Práctica Moderna, pág. 132; La Inoculación Vindicada, pág. 111; Ensayo Apologético, págs. 84-5 y 116-7.

$53 \quad$ O'Scanlan hace referencias frecuentes a las obras de destacados innovadores franceses en estas aplicaciones como son Bernoulli y D'Alembert, los primeros en aplicar el cálculo de probabilidades para entender el impacto de la enfermedad y su tratamiento. Sobre las diferencias en planteamientos entre estos últimos, véase Camilla Colombo y Mirko Diamantı, «The smallpox vaccine: the dispute between Bernoulli and d'Alembert and the calculus of probabilities», Lettera Matematica International 2 (2015), págs. 185-192. Véase también Riera y Granda-Juesas, La Inoculación de la Viruela en la España Ilustrada, Valladolid, Universidad de Valladolid, 1987, págs. 23-24; Duro Torruos, Los inicios, págs. 95-100.

54 «Finalmente la Divina Providencia en este felíz siglo manifestó la inoculacion, invencion de las mas útiles en mi sentir de quantos hallazgos médicos hasta ahora se han descubierto», O'SCANLAn, Práctica Moderna, pág. bl.

55 Por ejemplo, de su extensa biblioteca personal, solo hay constancia de 15 títulos en la Biblioteca Histórica de la Universidad Complutense, 10 que llevan, de su propia mano, la anotación «Ex libris Timoteo O'Scanlan» y otros 5 cuyos títulos figuran en una nota de entrega de un librero para el médico. A pesar de su escaso número, es indicativo que 8 están en lengua francesa, 3 en español, 3 en inglés y uno en latín. Por otro lado, sus tres libros propios están repletos de referencias a autores de distintas lenguas, incluyendo publicaciones periódicas (por ejemplo, Memorias anuales de organismos de distintos países y lenguas) muy coetáneas con las fechas en que dichos libros se publicaron. Véase Michael WhiтE, «New Developments in the life and works of Dr. Timoteo O’Scanlan», en García Hernán y Skowron (eds.), From Ireland to Poland, págs. 251-262; pág. 259.

56 «Hasta ahora juzgaba que no havia mas Estrangero en la Republica de las Letras, que los ignorantes. Todos los hombres Literatos en qualquiera parte del Globo que se hallen, son Conciudadanos, e individuos de esta Sociedad, contribuyendo por sus trabajos al adelantamiento de las Artes, i Ciencias [...] Inglaterra ha producido un Newton, España produjo otro en D. Jorge Juan», O’Scanlan, La Inoculación Vindicada, págs. 133-134. 
en el Palacio de Aranjuez ${ }^{57}$, algo que Calvo Maturana interpreta como una toma de postura oficial por la ciencia ${ }^{58}$.

Los datos y las estadísticas le llevan a O'Scanlan a otro tema central de la época y que aparece muy destacado en círculos intelectuales de las sociedades de «Amigos del País» y por el Gobierno, a saber, el ideario del bien público y el fortalecimiento del país que se nutriría de mejoras económicas y del aumento de la población. Una figura importante respecto a esto último con quien se alinea O'Scanlan es el poderoso político Pedro Rodríguez, Conde de Campomanes. No solo cita el conocido libro de éste ${ }^{59}$, Discurso sobre el fomento de la Industria Popular, sino que además le dedica al Conde su primer libro. Aprovecha para resaltar la gran contribución al aumento de la población que puede proporcionar la inoculación. Nuevamente, intenta llevar este asunto al terreno de la ciencia: partiendo de los datos contrastados de que dispone, calcula cifras globales de población que, en el caso de generalizarse la inoculación, pudiera librarse de la muerte a causa de las viruelas ${ }^{60}$. Además, no solo plantea la práctica para la Península sino que, muy consciente de los estragos que venía causando la viruela en los territorios hispanoamericanos, O’Scanlan ve en la inoculación un recurso para revertir la merma de la población en dichos territorios $^{61}$. Siempre se esfuerza en operar con datos certificados o por escrito - bien por cargos administrativos, militares o sacerdotes en las misiones- de la incidencia de la viruela y las inoculaciones habidas en aquellos territorios $^{62}$. Asimismo, Demerson documenta la aplicación en aquellos territorios del método elaborado por O’Scanlan en su primer libro ${ }^{63}$. La sintonía de

57 Gazeta de Madrid, 30 octubre, 87 (1792), pág. 767.

58 «In 1792, Charles IV took a stand for science by receiving doctor Timoteo O'Scanlan, author of an Ensayo apologético de la inoculación, at the Court»: Antonio Calvo Maturana, "Is it useful to deceive the people?' The Debate on Public Information in Spain at the End of the Ancien Régime (1780-1808)», The Journal of Modern History, 86 (March 2014), pág. 39.

59 Véase O'Scanlan, Ensayo Apologético, pág. 50. Campomanes apoya explícitamente la inoculación y su contribución al aumento de la población: «La inoculación que preserva tantos niños de ser víctimas de las viruelas, y es un remedio tan probado y certero, facilitará el aumento de la población si llegamos a vencer el terror pánico contra este remedio [...] ¿Qué disculpa podemos tener para no dar a la población tan importante auxilio?», Pedro Rodríguez Campomanes, Discurso sobre el fomento de la industria popular, Madrid, Imprenta de Antonio Sancha, 1774, págs. li-lii.

60 Aunque sus cálculos estadísticos son rudimentarios, extrapolando desde datos limitados para calcular cifras globales, no obstante parte de datos constatados y éstos apuntan a ganancias poblacionales que, sostiene, tienen gran potencial para fortalecer al ejército: «un ejército de 380.000 hombres (que excluídas las mugeres) podría formarse de las 760.000 personas conservadas con la Inoculacion, sería siempre muy respetable», O’Scanlan, Ensayo Apologético, pág. 50.

${ }_{61}$ Para un estudio global de los estragos de la viruela en todo el continente Americano, norte y sur, véase Elizabeth A. Fenn, Pox Americana, New York, Hill \& Wang, 2001.

62 Véase O'Scanlan, Ensayo Apologético, págs. 322-3.

63 Paula de Demerson, "La práctica de la variolación en España”, Asclepio, 45:2 (1993), págs. 3-39. 
los argumentos de los inoculadores con altas esferas del gobierno de Carlos III, entre otros factores, explica que, a pesar de que el protomedicato, argumentando los riesgos y peligros de la práctica, solicitara en distintas ocasiones la prohibición de la medida, ninguna de sus solicitudes recibió el beneplácito del Consejo de Castilla ${ }^{64}$. No obstante, a pesar del apoyo a la inoculación en la cúspide de la administración política ${ }^{65}$, llama la atención la tardanza de la monarquía borbónica española en adoptar la medida para consigo misma. En Francia, la Casa Real, a la muerte de Luis Xv en 1774 por viruelas, reaccionó a toda prisa inoculando al heredero, Luis $\mathrm{XvI}^{66}$. En cambio, a pesar de que la Casa Borbónica Española fuera severamente castigada por la enfermedad ${ }^{67}$, no toma una iniciativa similar hasta 1798 cuando, ante la preocupación por el contagio de una hija de Carlos Iv, la Infanta María Luisa, se procede a inocular al heredero, el futuro rey Fernando VII, y a sus dos hermanos, y oficialmente se tomaron medidas para facilitar la práctica general de la inoculación en los hospitales españoles ${ }^{68}$.

Finalmente, es importante señalar cómo O'Scanlan abordaba otra característica de la época, a saber, la fuerte oposición a la inoculación llevada a cabo desde postulados religiosos y la táctica de opositores a la práctica que se servían de ese argumento para influenciar la opinión pública. Combatía denodadamente ese planteamiento ${ }^{69}$, llevando la discusión al terreno del razonamiento, mostrando que, lejos de estar reñida con la doctrina cristiana, la inoculación era perfectamente compatible con esa doctrina. Para apoyar sus argumentos, recurre a varios comportamientos ejemplarizantes que proceden del mismo mundo

64 Incluso con anterioridad, el protomedicato había vetado en 1757 la publicación de la traducción al español, hecha por Rafael Osorio, de un libro clave y señero sobre el tema, Memoria sobre la inoculación de las viruelas de Charles Marie de La Condamine. Véase, Riera y Granda-Juesas, La Inoculación, págs. 23-24.

65 Un apoyo que venía de años atrás: por ejemplo, Ricardo Wall, ya en el año 1762, se declaraba claramente a favor de la medida. Véase, Riera y Granda-Juesas, La Inoculación, pág. 25.

66 Acontecimiento puntualmente puesto en conocimiento de Carlos III por el Embajador en París, el Conde de Aranda, Gaceta de Madrid, Número 28, 12 julio 1774.

67 En la familia real Borbónica española, las viruelas llevaron a la tumba al Rey Luis I en 1724 a los 17 años y al hijo de Carlos III, El Infante Don Gabriel en 1788 a los 36 años. En cuanto a consortes, la joven esposa de Luis I, Luisa Isabel de Orleans, se contagió durante la enfermedad de su marido, pero se recuperó. Al igual que su marido, el Infante Don Gabriel, su esposa, Mariana Victoria de Portugal, y el hijo de ambos, murieron de viruelas el mismo año, 1788. Las reinas Isabel de Farnesio y Bárbara de Braganza, aunque sobrevivieron a la enfermedad, llevaron sus secuelas corporales de por vida.

68 Véase Duro Torrijos, Los inicios, págs. 130-132.

69 Sabido es que su libro La Inoculación Vindicada se dedica a desmontar los postulados del presbítero Ferrer i Gorraiz, véase, Pilar León Sanz y Dolores Barettino Colama, Vicente Ferrer i Gorraiz Beaumont y Montesa (1718 -1792), Un Polemista Navarro de la Ilustración. Pamplona, Gobierno de Navarra, 2007 (especialmente págs. 203-270). 
católico. Por ejemplo, en primer lugar, resalta inoculaciones llevadas a cabo por religiosos entre las comunidades de indígenas en el nuevo mundo, particularmente el caso de un Carmelita en Pará (cerca de la hoy frontera de Brasil con Colombia), quien, ante una epidemia, recurrió él mismo a inocular y «salvó a la mitad de sus feligreses [...] habiendo muerto por Viruelas epidémicas la otra $\operatorname{mitad} \gg^{70}$. En segundo lugar, solicitó una reflexión por escrito a un catedrático de Teología de la Universidad de Santiago, quien afirmó que lo decisivo respecto a la aceptabilidad o el rechazo de la inoculación dependía de su utilidad ${ }^{71}$. En tercer lugar, dedica su último libro al Obispo de Barbate, quien apoyó decididamente la inoculación para frenar una epidemia en su diócesis ${ }^{72}$. Con esta estrategia, O'Scanlan persigue el doble objetivo de hacer al mundo de la religión Católica, particularmente al clero, aceptar y promover la inoculación ${ }^{73}$ y, a la vez, contrarrestar la idea de que todo ese mundo estaba monolíticamente en el campo de los anti-inoculadores. Por otro lado, es indicativo el hecho de que el autor más referenciado en los escritos de O'Scanlan sea quien se tiene como la gran figura literaria de la ilustración en España, el Padre Feijoó.

\section{Conclusiones}

La documentación inédita sobre Timoteo O’Scanlan que da a conocer este artículo abre perspectivas nuevas sobre la vida personal y familiar del médico $\mathrm{y}$, sobre todo, respecto a su patrimonio, cuestiones que, por regla general son muy características de la tipología de documentos testamentarios. A la vez, esta documentación nos ha provisto de datos para abordar una contextualización más fehaciente de su biografía, destacando los factores que le han permitido jugar un papel relevante en la España de la segunda mitad del siglo XVIII. En cuanto al primero, vimos que su vida personal y familiar estaba condicionada por el

70 O’SCanlan, Práctica Moderna, pág. 105 y Ensayo Apologético, pág. LIV. Este caso fue recogido por La Condamine en el transcurso de su viaje por aquellas tierras (1735-44) y destacado en su relato de ello. Véase Charles Marie De La Condamine, Viaje a la América Meridional, Madrid, Espasa Calpe, 1962, págs. 87-88.

71 O'Scanlan incluye este escrito del Dr. Fr. Joaquin Fontenla en su libro, La Inoculación Vindicada, págs. 215-217.

72 En su encomio al prelado, quien había apoyado la inoculación de su propio sobrino a modo de dar ejemplo, O'Scanlan manifiesta: «No satisfecho el zelo de V.S.I, con proporcionar á su Grey todos los auxilios espirituales que exige el perfecto desempeño del oficio pastoral, vela al mismo tiempo diligente sobre su temporal felicidad, promoviendo en su Obispado los saludables efectos de la Inoculación», O'Scanlan, Ensayo Apologético, pág. III.

73 En este respecto, O'Scanlan sigue las llamadas hechas al clero anglicano en Inglaterra por Buchan, y, como ya se ha dicho arriba, reproduce el capítulo del médico escocés sobre la inoculación en su último libro: O’Scanlan, Ensayo Apologético, págs. 270-297. 
quebranto de la salud mental de su esposa y la corta edad de sus hijos, dada su propia edad avanzada. El hecho de que los testamentos abarcan un período de veinte años da lugar a ciertos cambios en sus prioridades respecto a estas cuestiones, motivados por la evolución de las circunstancias con el transcurso del tiempo. En los primeros documentos, su prioridad era rodear a sus hijos con un tutor que podía situarles bien en la vida, mientras que en el último testamento la prioridad es asegurar que el patrimonio que les legaba les llegaría intacto. En cuanto a su mujer, mientras que el primer documento hacía provisión para que recibiera una dotación adicional a su herencia de nueve mil reales, en el caso de que enviudara, en los siguientes, debido a su demencia, lo que prima es asegurar su cuidado.

La fortaleza de la economía del médico es un dato totalmente novedoso que, por un lado, da testimonio de las buenas oportunidades económicas que brindaba la España de la época a los inmigrantes irlandeses y, por otro, abría interrogantes en cuanto a los orígenes de dicha economía, ya que parecía superar lo que podría esperarse de sus honorarios oficiales. El artículo pone de manifiesto distintas fuentes de ingresos adicionales —asistencia a particulares, alquileres por propiedades o sus publicaciones- pero al quedar constatada su participación con una suma importante en una operación comercial, y dadas sus estrechas relaciones con comerciantes de origen irlandés en Ferrol, se considera como hipótesis factible que hubiera podido participar también en otras operaciones comerciales beneficiándose de la pujanza económica del Ferrol del siglo XVIII. También, es significativo que los testamentos, debido a la amplitud del tiempo de su confección, han dejado constancia de que su patrimonio inmobiliario en Ferrol fue adquirido con anterioridad al año 1773 y, por lo tanto, con anterioridad a la época de su mayor reconocimiento por su labor contra la viruela.

En cuanto a su interacción con la política y la sociedad españolas de la época, hemos visto que operaba una doble pauta. Por un lado, contaba con una fuerte solidaridad entre sus paisanos de origen irlandés. Esto se constataba desde su colocación inicial como médico del Regimiento Hibernia, pasando por quienes informaban favorablemente para su paso a Primer Médico de los Hospitales Reales de Ferrol o, por ejemplo, cómo recurre a gentes de origen irlandés para velen por el futuro de sus hijos o para recabar datos e información profesional. Por otro lado, dada su posición de prestigio, otros inmigrantes irlandeses recurren a él en busca de apoyo para sus fines ${ }^{74}$. También, hemos visto cómo

${ }^{74}$ Hemos visto cómo Enrique Doyle acudió a O'Scanlan para que aportara contribución a su libro y el médico O’Sullivan buscó, desde Méjico, su mediacíon con la Academia de Medicina en Madrid: véase a Fiona 
el nexo de origen de la inmigración irlandesa facilitaba una transversalidad en relacionar personajes de distinta formación y ocupación dentro de la comunidad. O'Scanlan es, en sí mismo, un buen ejemplo, relacionándose con médicos, militares, religiosos, comerciantes y autores, entre otros.

En cambio, la otra pauta muestra a un O'Scanlan cómodamente inmerso en un mundo español. Su raigambre en el ejército y la marina le colocaba en una posición privilegiada en cuanto a influencia y relaciones transversales. El gran núcleo intelectual y cultural que el desarrollo de Ferrol y sus actividades desplazan a la ciudad no hace sino facilitar aún más esa transversalidad. Dados su gran saber y sus logros profesionales, O'Scanlan trasciende los confines de la inmigración para jugar un papel significativo en la sociedad española. Esto se constataba en hechos como que, además de asistir a necesitados ${ }^{75}$, sus servicios fueran requeridos por españoles relevantes, el que tuviera fácil acceso a la prensa española de la época, que estuviera muy integrado en instituciones españolas, como La Real Academia de Medicina, o que fuera recibido en persona por el rey. Clave con respecto a todo esto, podía haber sido, como he apuntado, su gran sintonía con idearios y objetivos fundamentales del dieciocho español, como, por ejemplo, la apuesta por la ciencia, la salud pública como pilar del bien público y el incremento de la población como medio para el fortalecimiento del país.

Sin duda O’Scanlan es un ejemplo destacado de integración de la inmigración irlandesa en la España del siglo XVIII. Supo beneficiarse de las oportunidades que se brindaba a esa inmigración ${ }^{76}$ para labrarse una exitosa carrera económica, profesional y social. Por otro lado, por su saber, su práctica médica y su gran labor en publicaciones, él también es un contribuyente neto a las mejoras en el campo de la salud de su país de acogida, país con el que profesaba una gran sintonía e identificación ${ }^{77}$. Convencido de que la inoculación constituía un punto de inflexión en la conquista de la viruela, encaró sus últimos años con la satisfacción de su propia labor en la promoción de la práctica y las

CLARK, «Advancing the medical career abroad: The case of Daniel O'Sullivan (1760 - c.1797)», en KeLLY and CLARK (eds.), Ireland and Medicine, págs.197-216.

75 Por ejemplo, inoculaba sin honorarios a pobres, afirmaba que se prestaba asistencia en el Hospital a toda persona que la pedía e incluso, ante la lacra social que suponía la situación de los niños expósitos en aquella época (véase Domínguez OrTiz, Carlos III, págs.139-140), le encontramos, junto con Ángela Álvarez, apadrinando a un niño expósito en Ferrol, quien se llamó Timoteo Ángel, por los nombres de padrino y madrina: véase Amenedo Costa, La población Británica, pág. 84.

76 Véase Mary Ann Lyons, \& Thomas O'Connor, Strangers to Citizens: The Irish in Europe 1600-1800, Dublin, The National Library of Ireland, 2008.

77 Su manera de referirse a España y a sus dominios se caracteriza con pronombre inclusivo — «nuestra España» y «nuestras Indias»— como si él fuese un español más. 
repercusiones que su obra iba teniendo ${ }^{78}$. Murió el 22 de agosto de $1795^{79}$, tres años antes de la gran innovación de la vacunación de Jenner ${ }^{80}$. Difícilmente hubiera podido imaginar semejante salto cualitativo, pero con su confianza en el progreso de la ciencia, ya contaba con avances significativos en la práctica: «el tiempo y la experiencia irán perfeccionando la inoculación» ${ }^{81}$. Por último, es interesante señalar que la reticencia de España en adoptar oficialmente la inoculación contrasta con la prontitud con que abrazaba la vacunación, siendo capaz de organizar, en un solo lustro desde su inicio en Inglaterra, una empresa de tal envergadura como La Real Expedición Filantrópica de la Vacuna ${ }^{82}$. Sin duda, la labor previa de los inoculadores allanó el camino y, de hecho, los compañeros de O’Scanlan en la Real Academia de la Medicina tuvieron un papel muy destacado en los pasos tempranos en favor de la vacuna en España ${ }^{83}$.

${ }_{78}$ Los censores nombrados por la Academia (Dr. Antonio Soldevilla y Dr. Ignacio María Ruíz de Luzuriaga) para informar sobre su último libro manifestaron al respecto de sus trabajos que «le harán mirar de la posteridad como un bienhechor de la humanidad» (incluido en su libro Ensayo Apologético, pág. XI).

79 AGMS, Leg. 0818, f.38, certificación de defunción, firmada por Josef Cayetano Chacon, cura de la Iglesia de San Luis Obispo.

80 La inoculación transmitía las viruelas al inoculado, aunque por regla general de una forma leve, mientras que la vacunación, de origen bovino y mucho menos agresiva, al no operar con el virus humano, no la transmitía, reduciendo en gran medida el factor riesgo y, no obstante, protegiendo al vacunado de contraer la enfermedad. Sin embargo, la vacunación también causó algún desenlace fatal y muy sonado era el caso del hijo único de la familia aristócrata del Conde de Castro Terreño, Marqués de Sonora, que supuso apuros para los inicios de la implantación de la práctica. Véase Duro Torrijos, Los inicios, págs. 247-254.

81 Timoteo O'Scanlan, Ensayo Apologético, pág. XXXIII.

82 Véase Susana María Ramírez MarTín, La mayor hazaña médica de la colonia. La Real Expedición Filantrópica de la Vacuna en la Real Audiencia de Quito, Quito, Ediciones ABYA-YALA, 1999; véase también Emilio Balaguer Perigüell y Rosa Ballester Añón, En el nombre de los niños. La Real Expedición Filantrópica de la Vacuna (1803-1806), Monografías de la Asociación Española de Pediatría (AEP), Núm. 2, 2003, págs. 84-85.

83 Muy en particular está la labor de Ignacio María Ruiz de Luzuriaga. Véase Duro Torrijos, Los inicios, págs. 295-328. Ignacio María era hijo de la gran figura del inicio de la inoculación en el País Vasco, Doctor Josef de Luzuriaga, quien suministró a O'Scanlan los datos de la práctica en dicho territorio. Véase O’Scanlan, Práctica Moderna, págs. 76-80. 